\title{
DESENVOLVIMENTO SUSTENTÁVEL E EDUCAÇÃO AMBIENTAL: UMA ANÁLISE COMPARATIVA ENTRE NATAL/BRASIL E CIDADE DE AVEIRO/PORTUGAL
}

\author{
Rylanneive Leonardo Pontes Teixeira ${ }^{1}$
}

\section{INTRODUÇÃO}

No contexto das implicações negativas provocadas pelo modo de produção capitalista e pela produção em larga escala, gerando possivelmente um desaparecimento dos recursos naturais, surgem as discussões e os debates no século $\mathrm{XX}$, mais precisamente nos anos 60 , sobre a questão ambiental, conforme pode ser observado em Dias (2009). Na abordagem que se tem sobre a questão ambiental, é traçada a discussão sobre a problemática ambiental, que, antes de 1962, era pouco discutida, passando a ganhar mais relevância de estudo e pesquisa com a obra "Silent Spring", de Rachel Carson (CARSON, 2010), citada em Pessoa e Câmara (2014 apud PESSOA, 2014). Com isso, não demorou muito para que começassem a emergir estudos e/ou eventos sobre a temática (CURI, 2011).

No ano de 1972, é criada a Conferência das Nações Unidas sobre o Meio Ambiente Humano; e, em 1987, publicado o Relatório "Nosso Futuro Comum", responsável por relevantes contribuições a respeito da adoção do desenvolvimento sustentável, isto é, de um modelo de desenvolvimento que privilegia a equidade social, a questão econômica e a preservação ambiental (PESSOA e CÂMARA, 2014 apud PESSOA, 2014). Entre as discussões promovidas por esses eventos e outros, estão a do desenvolvimento sustentável e da educação ambiental, temáticas que se relacionam ao passo que se busca uma educação ambiental na perspectiva de conservação e preservação do meio ambiente e seus recursos por meio da conscientização das populações para um planeta com melhor qualidade de vida.

Nesse sentido, o presente artigo versa acerca do desenvolvimento sustentável e da educação ambiental, tendo por finalidade analisar o 
desenvolvimento sustentável e a educação ambiental em Natal/RN e na cidade de Aveiro/PT numa perspectiva comparativa, levando em consideração, para isso, a concepção das pessoas das referidas cidades.

Esse trabalho é composto, juntamente com a introdução e as conclusões, por três momentos: o primeiro responsável pelo levantamento do referencial teórico, onde são discutidos o desenvolvimento sustentável e a educação ambiental nos cenários brasileiro e português; o segundo traz os procedimentos metodológicos utilizados; e o terceiro possibilita a apresentação e discussão dos resultados obtidos com a perspectiva das populações de Natal e da cidade de Aveiro quanto ao desenvolvimento sustentável e à educação ambiental em suas respectivas cidades.

\section{NATAL E CIDADE DE AVEIRO: UMA BREVE CARACTERIZAÇÃO AMBIENTAL}

As cidades de Natal e Aveiro, localizadas em continentes distintos (a primeira na América do Sul e, a segunda, na Europa), consistem, respectivamente, nas capitais do estado do Rio Grande do Norte (RN), no Brasil, e do distrito de Aveiro, em Portugal. Elas apresentam algumas atividades econômicas em similaridade (como é o caso do turismo, pautado em áreas naturais: em Natal, nas praias; e, na cidade de Aveiro, na Ria - "Ria de Aveiro"), porém, algumas divergências se fazem presentes, por exemplo, quanto aos aspectos ambientais.

No que tange o contexto ambiental, Quintão, Moreto e Soares (p. 49) assinalam que, como "fruto do seu patrimônio natural, do seu tecido económico, da sua oferta cultural e das vivências urbanas que proporciona", a cidade de Aveiro consiste em uma dos municípios de Portugal com melhor oferta de qualidade de vida. Os autores referenciados apontam ainda que a cidade de Aveiro é servida por um Porto, considerada uma cidade de água e reconhecida, por muitas pessoas, como a Veneza de Portugal. É nesse aspecto, de relação entre a cidade e a sua Ria, que a cidade é conferida como exemplo de equilíbrio ambiental (QUINTÃO, MORETO E SOARES).

Já no tocante à Natal, podemos perceber que a mesma possui políticas públicas (projetos, programas e/ou planos), sejam "de arquivo" ou estruturais, voltadas para o desenvolvimento sustentável, visando à conservação do meio ambiente da cidade e seus recursos; no entanto, não é considerada, a nível nacional, uma das cidades mais sustentáveis ou com melhor oferta de qualidade de 
vida. Dentre as políticas, podemos citar o Plano Municipal de Redução de Riscos (PMRR) do município de Natal e o Conselho Municipal de Planejamento Urbano e Meio Ambiente (CONPLAM) de Natal.

\section{Desenvolvimento sustentável e educação ambiental: uma análise centrada no Brasil e em Portugal}

$\mathrm{Na}$ sociedade contemporânea brasileira, a ação humana vem acometendo o meio ambiente e sua qualidade, podendo atingir, desta forma, a sustentabilidade deste meio. Como sabemos, uma forma de reverter esse quadro do Brasil, mas também de outros países na mesma situação, é a inserção da educação ambiental, sobretudo nas escolas e em seus projetos. Nesse sentido, Jacobi (2003) aponta que as ações do homem, quando num contexto de degradação ambiental, criam uma articulação com a produção de educação ambiental.

Sabendo que a maioria das pessoas do país vive em cidades, e tomando isso como referência, observa-se um progressivo aumento de ações de degradação das condições de vida, o que nos faz refletir a respeito do pensar e agir sobre a questão ambiental atual (JACOBI, 2003).

Relativo a essa discussão, o autor referenciado assinala que a dimensão ambiental é configurada como um ramo do conhecimento que envolve um conjunto de atores/sujeitos da educação, desenvolvendo, por exemplo, a universidade e sua comunidade numa perspectiva interdisciplinar. Nessa vertente, percebemos, ainda segundo Jacobi (2003), que a produção de conhecimento deve contemplar as interrelações entre os meios natural e social, abrangendo:

[...] a análise dos determinantes do processo, o papel dos diversos atores envolvidos e as formas de organização social que aumentam o poder das ações alternativas de um novo desenvolvimento, numa perspectiva que priorize novo perfil de desenvolvimento, com ênfase na sustentabilidade socioambiental (JACOBI, 2003, p. 190).

A partir dessas discussões, observamos que a educação ambiental é um campo do conhecimento que vem apresentando abordagens as quais buscam, em suas ações e práticas, medidas voltadas para o desenvolvimento sustentável. 0 pioneiro dos estudos a respeito da educação ambiental desde a geração préEstocolmo, Scoullos, verifica que "a ideia da proteção ambiental nunca foi cortada da 
ideia ou da necessidade de um tipo especial de desenvolvimento" (SCOULLOS, 1995 apud SAUVÉ, 1997, p. 1).

Sauvé (1997) aborda sobre a Educação Ambiental Para o Desenvolvimento Sustentável (EAPDS), percebendo que a educação ambiental atrela-se ao desenvolvimento sustentável, podendo tal relação, porém, ser observada sob as mais variadas perspectivas, conforme é indicado a seguir:

Para alguns, o DS é o objetivo mais ambicioso da EA, assim, o termo Educação Ambiental Para o Desenvolvimento Sustentável (EAPDS) é proposto. Para outros, o DS refere-se aos objetivos específicos, que deve ser adicionado para a EA, assim, utilizam a expressão educação para 0 ambiente "e" para o desenvolvimento sustentável. Para a UNESCO, num documento proposto durante a Eco-92, a EA é apenas uma das temáticas que contribui para o DS. Ainda para outros, o termo EA implicitamente inclui a educação para o DS e, portanto, a mudança da terminologia faz-se desnecessária. [...] Finalmente, a expressão "educação sobre o $D S$ " é encontrada na literatura: o DS transforma-se no ponto central da análise crítica (SAUVÉ, 1997, p. 7).

De acordo, ainda, com Suavé (1997), assinalada em Teixeira (2015), os conceitos de educação ambiental e de desenvolvimento sustentável vêm sendo relacionados quando falamos da promoção de modelos que tomam como base 0 uso dos recursos, levando em consideração, em particular, a equidade e a durabilidade.

Em relação ao cenário português, a educação ambiental, no país de Portugal, começou a ser desenvolvida em especial no transcorrer da década de 90 (PINTO, 2004), sendo explorada, mais precisamente, em 1975 através, entre outros, de projetos nas escolas (FREITAS, 2006). No campo de estudo da dimensão ambiental da educação, são visíveis um conjunto de atividades de caráter cívico e educacional, e determinações do governo vinculadas a tais atividades.

Em Portugal, desde o ano de 1948, há movimentos sociais sobre educação ambiental, os quais discutem a conservação da natureza e de seus recursos (PINTO, 2004). Nesse sentido, Freitas (2006) aponta que a política pública de ambiente do país é avaliada a partir de um ministério, o qual se voltaria primordialmente para as questões do ambiente, passando a contar, posteriormente, 
com uma Secretaria de Estado do Ambiente, a qual tutela uma Comissão Nacional do Ambiente (CNA) ${ }^{2}$ (FREITAS, 2006).

Embora haja movimentos sobre educação ambiental desde 1948, a institucionalização da educação ambiental, em Portugal, só veio acontecer, de fato, em 1975, com a dinamização do Serviço Nacional de Participação das Populações, conforme é assinalado em Freitas (2006).

O quadro 1 - "Projectos escolares de EA implementados em Portugal (1997/2000) e apoiados pelo IPAMB" -, apresentado na leitura desse último autor referenciado, mostra que a educação ambiental trata-se de uma temática discutida nas escolas portuguesas, com a inserção, em 1997, de 219 projetos escolares.

Ainda de acordo com ele, a educação ambiental em Portugal é discutida de forma integrada com o desenvolvimento sustentável, dando origem ao que se denomina de Educação para o Desenvolvimento Sustentável (EDS). É nesse contexto de relações entre o desenvolvimento sustentável e a educação ambiental que o autor aponta que, apesar de a maioria dos especialistas do âmbito da EDS encará-lo como um novo estado evolutivo ou uma nova geração de Educação Ambiental (EA), existem outras perspectivas:

\footnotetext{
Caride, e Meira (2004), por exemplo, argumentam que «a Educação Ambiental para o Desenvolvimento Humano Sustentado, ou como se queira denominar, arrastada pela sedução destes conceitos, poderá derivar numa perigosa indefinição...» (p. 197), e realçam o perigo de que «debaixo de um discurso aparentemente comprometido com a mudança social [...] se pode estar salvaguardando a mesma orientação de desenvolvimento, da cultura e da política económica que tem gerado os problemas sócio-ecológicos existentes» (p. 198). Defendendo que «os enquadramentos que propiciam o saber e o saber fazer educativo-ambiental não poderão restringir-se apenas a suscitar atitudes nas pessoas para um desenvolvimento sustentável» ( $p$. 278), parecem encaminhar-se mais no sentido de considerar a EDS como uma parte da EA (Freitas, no prelo b). McKeown, e Hopkins (2002), por seu turno, defendem que a EDS e a EA «têm similaridades», mas são abordagens «distintas, ainda que complementares», e que é importante que «a EA e a EDS mantenham agendas, prioridades e desenvolvimentos programáticos diferentes (FREITAS, 2006, p. 139).
}

\footnotetext{
2 A Comissão Nacional do Ambiente (CNA), criada no ano de 1971, com funções e atividades direcionadas à informação e sensibilização ambiental, é um das consequências institucionais com maior visibilidade no que diz respeito aos resultados da participação portuguesa na Conferência das Nações Unidas sobre o Meio Ambiente Humano (PINTO, 2004).
} 
A educação ambiental, em Portugal, é relacionada ao desenvolvimento sustentável, entretanto, apresenta abordagens distintas em relação ao último, mesmo que se complementando.

O desenvolvimento sustentável é mundialmente conceituado, pela Comissão Mundial sobre Meio Ambiente e Desenvolvimento (CMMAD), como aquele modelo de desenvolvimento que é capaz de suprir as necessidades da geração do presente, sem comprometer as do futuro, sendo dependente do planejamento e reconhecimento da finitude dos recursos naturais, conforme é apontado pela WWF. A educação ambiental, no contexto do desenvolvimento sustentável, é inserida na sociedade atual como um possível instrumento de viabilização da sustentabilidade, constituindo-se em uma forma de colocar em prática as ações sustentáveis realizadas pelo governo desde as escolas.

\section{METODOLOGIA}

O presente artigo segue as orientações de uma pesquisa com abordagem qualitativa, visto que serão traçados e descritos aspectos de duas situações sociais (pesquisa descritiva), as quais passarão por processos de caráter exploratório (pesquisa exploratória) (POUPART et al., 2014). A metodologia desse trabalho é constituída, também, por um estudo comparativo, método de pesquisa este que tem por finalidade, dentre outras, investigar as diferenças e semelhanças entre duas situações.

O recorte territorial desse estudo é constituído por duas cidades: Natal e cidade de Aveiro, situadas, respectivamente, no Brasil e em Portugal. Os atores chaves para a pesquisa e, posteriormente, o desenvolvimento desse trabalho são os indivíduos dessas cidades. Caso necessite a identificação de cada indivíduo juntamente com as respectivas datas de resposta ao questionário, temos os citados a seguir, divididos em dois grupos (brasileiros e portugueses): 1. Indivíduo Brasileiro 1 (IB1) - no dia 06 de março de 2016, Indivíduo Brasileiro 2 (IB2) - no dia 06 de março de 2016, Indivíduo Brasileiro 3 (IB3) - no dia 06 de março de 2016, e Indivíduo Brasileiro 4 (IB4) - no dia 07 de março de 2016; e 2. Indivíduo Português 1 (IP1) - no dia 08 de março de 2016, Indivíduo Português 2 (IP2) - no dia 08 de março de 2016, Indivíduo Português 3 (IP3) - no dia 09 de março de 2016, e Indivíduo Português 4 (IP4) - no dia 09 de março de 2016. 
O instrumento de coleta de dados empregado foi o questionário, o qual é responsável por indagar questões a pessoas aleatórias sobre as temáticas de desenvolvimento sustentável e educação ambiental, sobretudo numa vertente de correlação. Os questionários, oito em sua totalidade, são compostos por questões abertas, as quais vão desde o conceito de desenvolvimento sustentável à como se dá a inserção da educação ambiental no campo desse modelo de desenvolvimento. No momento dessa coleta, não foi realizada a identificação de cada indivíduo, o qual recebeu um código na intenção de manter o seu anonimato (GOMES, 2005 et al. apud MINAYO, ASSIS e SOUZA, 2005).

\section{DESENVOLVIMENTO SUSTENTÁVEL E EDUCAÇÃO AMBIENTAL: UMA ANÁLISE A PARTIR DA PERSPECTIVA DAS POPULAÇÕES DE NATAL/BR E CIDADE DE AVEIRO/PT}

Neste item, haverá a apresentação e discussão dos dados obtidos através da aplicação dos questionários com os indivíduos de cada cidade, Natal e cidade de Aveiro. A partir deles, nos foi possível observar uma visão geral das concepções das populações sobre desenvolvimento sustentável e educação ambiental como dois caminhos interligados, na busca da conscientização das pessoas para o cuidado com o planeta.

A partir da análise dos indivíduos de Natal, percebemos que há uma convergência de ideias sobre o conceito de desenvolvimento sustentável por parte de entrevistados, seguindo o que está estabelecido na CMMAD: desenvolvimento sustentável consiste naquele modelo de desenvolvimento que faz uso dos recursos naturais pensando não só atual geração, mas também na do futuro, tendo por objetivo não esgotar os recursos da natureza para a população futura. Os cidadãos portugueses também seguem esse conceito, assinalando que tal desenvolvimento permite uma boa de qualidade de vida nos âmbitos ambiental, social e econômico.

Sobre o que pensam acerca do desenvolvimento sustentável, todos os indivíduos, com exceção de um, discutiram a questão partindo do viés de sua importância para o hoje e, principalmente, o amanhã. Nesse sentido, pudemos perceber que o desenvolvimento sustentável é indispensável para a geração futura, constituindo ações de preservação, cuidado e mantimento do meio ambiente nas condições mais adequadas, para que as gerações futuras possam desfrutar de tais 
ações. O IP2 (2016) pensa que essa forma de desenvolvimento "pode ter muitos sentidos. É algo que entrou na moda e do que se fala muito sem muitas vezes ter uma noção do que é. Começa a ser um conceito banalizado e só serve de factor embelezador dos discursos".

No que se refere aos principais responsáveis pelo desenvolvimento sustentável e pela degradação do meio ambiente, observamos, de forma generalizada, que o principal responsável por ações concernentes tanto ao desenvolvimento sustentável quanto à degradação ambiental é o ser humano. No entanto, dois entrevistados, um de Natal e um da cidade de Aveiro, especificaram suas respostas, fragmentando-as em dois grupos: o primeiro à população, ao governo, à sociedade civil organizada e às empresas; já o segundo aponta que é através das atividades desenvolvidas pelos humanos nas empresas (de transportes, resíduos e afins, indústrias, entre outros) que o meio ambiente vem a ser beneficiado ou prejudicado.

Tanto na capital do RN quanto na do distrito de Aveiro, as populações acreditam que a reciclagem e a separação do lixo por categorias não são capazes, por si só, de sanar a problemática da degradação do meio ambiente, fazendo-se necessárias outras medidas para solucionar ou, pelo menos, amenizar os problemas e/ou desafios atrelados, direta ou indiretamente, à destruição deste meio. Seguindo essa linha de discussão, consideramos que a reciclagem e a separação do lixo por categorias, embora não solucione o problema da degradação ambiental, configuramse em uma medida eficaz para, no mínimo, diminuir os desafios que meio ambiente vem perpassando no que diz respeito a sua degradação.

Ainda nesse contexto, o IP1 (2016, p.1) responde:

De fato, a separação do lixo por categorias é muito importante para evitar a degradação ambiental. Contudo, não é suficiente, pois a qualidade ambiental é muito mais abrangente, vai desde a gestão dos recursos hídricos, gestão das emissões gasosas e qualidade do ar, gestão dos resíduos e poluição sonora.

O IB3 também comenta que a reciclagem e a separação do lixo por categorias não respondem ao problema de destruição do meio ambiente, assinalando que, para a solução deste problema, fazem-se necessárias ações voltadas à educação ambiental, conscientização da sociedade e fiscalização: 
Não. O fator determinante do problema da degradação não é somente o lixo. Veja que, se reciclar fosse o suficiente, o problema estaria sanado. Precisa-se de educação ambiental, conscientização da sociedade e, até mesmo, fiscalização do que está sendo feito sobre e no ambiente.

A educação ambiental, consistente em um campo do conhecimento que anda lado a lado com as discussões referentes à degradação do meio ambiente, pode ser inserida no ramo do desenvolvimento sustentável. Isso pode ser percebido, na perspectiva dos indivíduos de Natal e cidade de Aveiro, quando eles assinalam que a educação ambiental e seus projetos partem das escolas por meio de práticas e políticas educativas, situando, desta forma, o ambiente escolar como um meio de inserção da educação ambiental no contexto das ações e práticas sustentáveis.

No cenário da cidade de Aveiro, ao contrário dos de Natal, todos os indivíduos entrevistados acreditam que a educação ambiental possa ser inserida no contexto do desenvolvimento sustentável através de ações pontuais, especialmente, nas escolas, passando conhecimentos a respeito de educação ambiental e desenvolvimento sustentável como formas de caminhar conjuntamente na busca da conscientização da população do planeta para o melhor cuidado dele. A leitura de Freitas (2006) vem a confirmar que a educação ambiental em Portugal surge, sobretudo, nas escolas e em seus projetos.

\section{CONCLUSÕES}

Mundialmente conhecido como aquele modelo de desenvolvimento que não privilegia apenas as populações da geração do presente, mas, também, as do futuro, o desenvolvimento sustentável associa-se à educação ambiental no sentido de procurarem a melhor qualidade de vida do meio ambiente e seu ecossistema através da conservação e preservação deste determinado meio. Mesmo que abordadas sob diversas perspectivas, a educação ambiental e o desenvolvimento sustentável consistem em temáticas discutidas em todo o mundo, estando voltadas para a conscientização da população sobre a conservação e preservação do meio ambiente e seus recursos.

Num sentido empírico, percebemos que as perspectivas dos entrevistados são, de maneira geral, convergentes, apresentando similaridades desde a concepção do conceito de desenvolvimento sustentável até como a educação ambiental pode ser inserida no contexto dessa forma de desenvolvimento. 
É nesse aspecto que comentamos que, embora as divergências existam, os pontos de vista dos entrevistados, de Natal e da cidade de Aveiro, se assemelham em sua visão geral.

O estudo aqui realizado pretende servir para o entendimento da interrelação existente entre as temáticas do desenvolvimento sustentável e da educação ambiental, buscando compreendê-las como campos do conhecimento que, juntos, contribuem para a análise da conscientização das pessoas no que tange à preservação do meio e seus recursos (considerados, nos dias de hoje, finitos), permitindo, com isso, que novas gerações sejam criadas com uma mentalidade conservacionista e capaz de implementar, no futuro, políticas que almejem o uso sustentável dos recursos do planeta. Todavia, precisamos, no presente, coibir ações ou práticas de degradação ou destruição do meio onde vivemos, como foi apontado importante nos apontamentos dos entrevistados.

\section{REFERÊNCIAS}

CARSON, Rachel. Primavera silenciosa. São Paulo: Gaia, 2010.

CURI, Denise. Gestão ambiental. São Paulo: Pearson Prentice Hall, 2011.

DIAS, Reinaldo. Gestão ambiental: responsabilidade social e sustentabilidade. São Paulo: Atlas, 2009.

INDIVÍDUO BRASILEIRO 1 (IB1). Natal/RN, 06 de março de 2016.

INDIVÍDUO BRASILEIRO 2 (IB2). Natal/RN, 06 de março de 2016.

INDIVÍDUO BRASILEIRO 3 (IB3). Natal/RN, 06 de março de 2016.

INDIVÍDUO BRASILEIRO 4 (IB4). Natal/RN, 07 de março de 2016.

INDIVÍDUO PORTUGUÊS 1 (IP1). Cidade de Aveiro/Distrito de Aveiro, 08 de março de 2016.

INDIVÍDUO PORTUGUÊS 2 (IP2). Cidade de Aveiro/Distrito de Aveiro, 08 de março de 2016.

INDIVÍDUO PORTUGUÊS 3 (IP3). Cidade de Aveiro/Distrito de Aveiro, 09 de março de 2016.

INDIVÍDUO PORTUGUÊS 4 (IP4). Cidade de Aveiro/Distrito de Aveiro, 09 de março de 2016. 
FREITAS, Mário. Educação Ambiental e/ou Educação para o Desenvolvimento Sustentável? Uma análise centrada na realidade portuguesa. Revista iberoamericana de educación, n. 41, p. 133-147, 2006.

JACOBI, Pedro. Educação ambiental, cidadania e sustentabilidade. Cadernos de Pesquisa, n. 118, p. 189-205, 2003.

MINAYO, Maria Cecília; ASSIS, Simone Gonçalves de; SOUZA, Edinilsa Ramos de. Avaliação por triangulação de métodos: abordagem de programas sociais. I MINAYO, Maria Cecília; ASSIS, Simone Gonçalves de; SOUZA, Edinilsa Ramos de. Rio de Janeiro (ORGs.): Editora Fiocruz, 244p, 2005.

PESSOA, Zoraide S.; CAMARA, H. R. S.. Sustentabilidade urbana e vulnerabilidade socioambiental: o caso da cidade de Mossoró/RN. In: Zoraide Souza Pessoa. (Org.). Sociedade e Ambiente: território, desigualdade e vulnerabilidade. 1ed. São Paulo: Livraria da Física, 2014, v. 1, p. 143-162.

POUPART, Jean et al. A pesquisa qualitativa: enfoques epistemológicos e metodológicos. Vozes, 2014.

QUINTÃO, José; MORETO, Maria João; SOARES, António. Aveiro - Uma visão integrada da mobilidade urbana. Disponível em: <http://www.cmsantarem.pt/ordenamento/projectos/Documents/4.\%C2\%BA\%20Congresso\%20Inter nacional\%20da\%20Rede\%20CIUMED/MUNIC\%C3\%8DPIO\%20DE\%20AVEIRO\%2 $0 \% 20-$

\%20Aveiro\%20\%E2\%80\%93\%20Uma\%20vis\%C3\%A30\%20integrada\%20da\%20m obilidade\%20urbana.pdf>. Acesso em: 08 jun. 2016.

RAMOS-PINTO, Joaquim. Educação Ambiental em Portugal: Raízes, influências, protagonistas e principais acções. Educação, Sociedade \& Culturas, v. 21, p. 151165, 2004.

SAUVÉ, Lucie. Educação Ambiental e Desenvolvimento Sustentável: uma análise complexa I. Revista de Educação Pública, v. 10, 1997. Disponível em: <http://www.ufmt.br/revista/arquivo/rev10/educacao_ambiental_e_desenvolvim.html> . Acesso em: 02 jun. 2016.

TEIXEIRA, R. L. P.. DESENVOLVIMENTO SUSTENTÁVEL NO BRASIL: UM OLHAR CRUZADO COM A EDUCAÇÃO AMBIENTAL. In: II Congresso Nacional de Educação, 2015, Campina Grande. Anais II CONEDU. Campina Grande: Realize, 2015. v. 2.

WWF. 0 que é desenvolvimento sustentável?. Disponível em: <http://www.wwf.org.br/natureza_brasileira/questoes_ambientais/desenvolvimento_s ustentavel/>. Acesso em: 10 jun. 2016. 